\title{
sciendo
}

\section{TECHNICAL, BIOLOGICAL AND MOLECULAR ASPECTS OF SOMATIC CELL NUCLEAR TRANSFER - A REVIEW}

\author{
Patrycja Mrowiec', Monika Bugno-Poniewierska \\ Department of Animal Reproduction, Anatomy and Genomics, Faculty of Animal Science, \\ University of Agriculture in Krakow, Al. Mickiewicza 24/28, 30-059 Kraków, Poland \\ •Corresponding author: patrycja.mrowiec7@gmail.com
}

\begin{abstract}
Since the announcement of the birth of the first cloned mammal in 1997, Dolly the sheep, 24 animal species including laboratory, farm, and wild animals have been cloned. The technique for somatic cloning involves transfer of the donor nucleus of a somatic cell into an enucleated oocyte at the metaphase II (MII) stage for the generation of a new individual, genetically identical to the somatic cell donor. There is increasing interest in animal cloning for different purposes such as rescue of endangered animals, replication of superior farm animals, production of genetically engineered animals, creation of biomedical models, and basic research. However, the efficiency of cloning remains relatively low. High abortion, embryonic, and fetal mortality rates are frequently observed. Moreover, aberrant developmental patterns during or after birth are reported. Researchers attribute these abnormal phenotypes mainly to incomplete nuclear remodeling, resulting in incomplete reprogramming. Nevertheless, multiple factors influence the success of each step of the somatic cloning process. Various strategies have been used to improve the efficiency of nuclear transfer and most of the phenotypically normal born clones can survive, grow, and reproduce. This paper will present some technical, biological, and molecular aspects of somatic cloning, along with remarkable achievements and current improvements.
\end{abstract}

Key words: nuclear transfer, animal cloning, nuclear reprogramming, telomeres, donor cells

The first mammal cloned by somatic cell nuclear transfer (SCNT) was Dolly the sheep in 1996 (Wilmut et al., 1997). As has been recently reported by Czernik et al. (2019), in the last several decades 24 mammalian species have been successfully cloned, including cattle (Cibelli et al., 1998), mice (Wakayama et al., 1998), goats (Baguisi et al., 1999), pigs (Poleajeva et al., 2000), rabbits (Chesne et al., 2002), cats (Shin et al., 2002), mules (Woods et al., 2003), horses (Galli et al., 2003), rats (Zhou et al., 2003), dogs (Lee et al., 2005), ferrets (Li et al., 2006), red deer (Berg et al., 2007), camels (Wani et al., 2010), and monkeys (Liu et al., 2018). Along with this success, SCNT has progressed from being a novel technology to a widely used 
technique for many purposes in mammals e.g.: rescue of endangered or extinct animals (Gómez et al., 2004, 2008; Samiec, 2005 a; Folch et al., 2009), replication of superior farm animals (Gambini and Maserati, 2018), production of genetically engineered animals (Samiec and Skrzyszowska, 2011 a; Luo et al., 2015), creation of biomedical models (Park et al., 2015), basic research (Schaetzlein et al., 2004; NowakImialek et al., 2011), biomedicine and biopharmacy (Chen et al., 2003; Samiec and Skrzyszowska, 2011 b; Tachibana et al., 2013; Loi et al., 2016). The mouse was the third mammal for which cloning was successful. Mouse model SCNT experiments have provided crucial information about the molecular events orchestrating SCNT, contributing to technical improvements and practical application of current cloning techniques in domestic and wild animals, e.g. X chromosome inactivation (Eggan et al., 2000), reprogramming of genomic imprinting (Mann et al., 2003), and chromatin remodeling and reprogramming (Kishigami et al., 2006).

Excluding cattle, the efficiency of cloning (the number of live offspring as a proportion of embryos transferred) in other mammalian species remains relatively low. Usually, around 1 to $5 \%$ of cloned embryos transferred into surrogate mothers develop to term. Most embryos die during gestation as a result of placental abnormalities (Khammanit et al., 2008; Dalman et al., 2010; Loi et al., 2016). Moreover, aberrant developmental patterns during or after birth are observed in cloned animals including symptoms such as placentomegaly, pulmonary hypertension, respiratory problems, cardiovascular insufficiency, immunodeficiency, and heart or liver failure (Hill, 2014; Loi et al., 2016). Researchers attribute these abnormal phenotypes mainly to incomplete nuclear remodeling, resulting in incomplete reprogramming (Rideout et al., 2001; Mann and Bartolomei, 2002; Samiec and Skrzyszowska, 2018 a).

The low efficiency of cloning means that a large number of embryos would be needed to be sure of success. In the case of the first viable cloned mammal, out of 247 donor cells fused with manipulated oocytes, 29 developed into blastocyst embryos, which were transferred into 13 surrogate mothers. Only 1 pregnancy ended successfully, with the birth of a 13.23-pound lamb (Wilmut et al., 1997). Dolly was healthy, raised six lambs of her own and had an average ovine lifespan. Normal pre- and postnatal development to maturity of cloned animals is the definitive measure of successful nuclear transfer and the ultimate confirmation of the value of this technology.

Multiple factors influence the success of each step of the somatic cloning process: from the donor nucleus, recipient cytoplast preparation, and embryo culture to transfer of cloned embryos into recipient females and neonatal management (Hill, 2014; Samiec and Skrzyszowska, 2018 b).

\section{Technical aspects of SCNT}

\section{Standard procedure for SCNT}

SCNT requires a series of technically difficult procedures to be accomplished, and many factors influence the success of cloning. Each technical step is crucial, therefore, improving/modifying each stage of the SCNT procedure is a topic of great interest to researchers and many approaches have been undertaken concerning the technical aspects. Recent improvements of technical steps are summarized in Table 1 . 


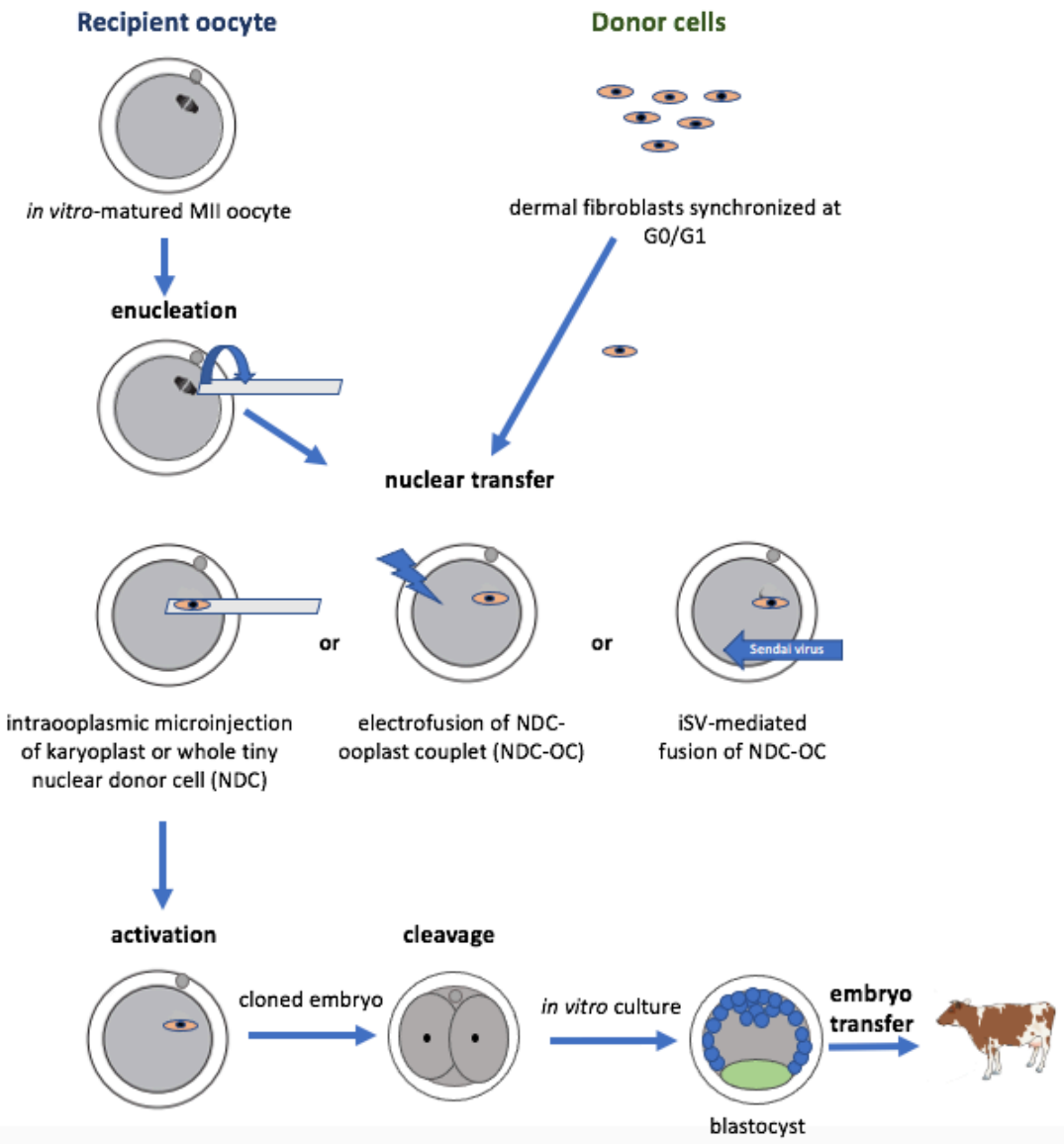

Figure 1. Schematic diagram of the somatic cell nuclear transfer (SCNT)

Before SCNT, the cell cycle of fibroblasts is synchronized at the G0/G1 stage. In vitro-matured metaphase II (MII)-stage oocyte is subsequently enucleated, and donor cell is introduced into the perivitelline space of an enucleated oocyte and fused with ooplast (by electrofusion or using inactivated Sendai virus; iSV) or directly microinjected into a cytoplasm of the enucleated host oocyte. Then, nuclear-transferred (reconstructed) oocyte is activated, and cultured in vitro until blastocyst formation. Subsequently, the embryo is transferred into a recipient female, and cloned animal is born after completion of gestation

The initial stage of the standard somatic cloning procedure is nuclear donor cell preparation, namely establishment of donor cell lines (differentiated foetal or adult somatic cell lines or undifferentiated foetal or adult stem cell lines) and their mitotic cycle synchronization. For example, fibroblast cell lines are established from primary cell cultures of skin explants obtained via biopsy. These cell lines are an enormously valuable source of nuclear material since they are easy to isolate, robust, grow fast ex vivo (Wong et al., 2007), and can be cryopreserved, stored in liquid nitrogen and used at a later time. Before SCNT, the cell cycle of fibroblasts is synchronized at the G0/G1 stage (Figure 1) which is considered to be appropriate for 
facilitating coordination in the cell cycle of the somatic nuclei, cytoplasm of oocytes and ensuring correct ploidy after nuclear transfer (Campbell et al., 1996 a; Ma et al., 2014). Also, according to Campbell et al. (1996 a), when a cell is in quiescence, the chromatin becomes more condensed, there is a reduction in transcription and translation, and mRNAs are actively degraded. Quiescence of donor cells is induced by 3-5 days of serum starvation in culture medium with a low content of serum $(0.3-0.5 \%)$ (Khammanit et al., 2008; Samiec et al., 2013 a, b) or by 3-5 days of contact inhibition (Samiec and Skrzyszowska, 2013; Shufaro and Reubinoff, 2017).

Recipient oocytes are usually obtained from abattoir ovaries or ovaries recovered from animals subjected to ovariectomy in veterinary clinics. The oocytes are cultured in vitro to reach metaphase II stage (MII) of meiosis, which is the most appropriate stage for the production of viable embryos. The time required for in vitro maturation culture is species-specific, e.g., 23 to 24 h for bovine (Vajta et al., 1996; Opiela et al., 2017), caprine (Skrzyszowska and Samiec, 2020) and feline (Skrzyszowska et al., 2002; Gómez et al., 2003) or 42 to 44 h for porcine oocytes (Samiec, 2004; Yuan and Krisher, 2012). In vitro maturated oocytes are subjected to removal of MII chromosomes - the step collectively called "enucleation" - employing a micromanipulator to suck out small portions of ooplasm apposed to the first polar body, where the MII chromosomes are situated (Niemann and Lucas-Hahn, 2012).

Next, the entire, intact and synchronized donor cell is isolated from its culture flask by cell dissociation reagents (e.g., trypsin, accutase) and introduced into the perivitelline space to form couplet of an enucleated oocyte (ooplast) and nuclear donor cell intended for plasma membrane fusion (Wilmut et al., 1997; Ogura et al., 2000) or deposited directly into the recipient ooplasm by a micromanipulator (Lee et al., 2003), or the karyoplast (previously isolated from whole nuclear donor cell) is microinjected directly to the host ooplasm using either piezo-driven device (Choi et al., 2002; Tanabe et al., 2017) or mechanical device, i.e., hydraulic micropump (Samiec and Skrzyszowska 2005 a, b, 2010 a). For ooplast-nuclear donor cell couplets, plasma membranes of the enucleated oocyte and donor cell are fused by short, high voltage pulses of electricity (Skrzyszowska et al., 2008; Skrzyszowska and Samiec, 2020), or using inactivated Sendai virus (i.e., fusogenic hemagglutinating virus of Japan (HVJ) envelope (HVJ-E)) (Liu et al., 2018). Then, nuclear-transferred (reconstructed) oocytes are activated either by strontium chloride (Wakayama and Yanagimachi, 2001; Tanabe et al., 2017) or by short electrical pulses in the presence of calcium ions (Lee et al., $2010 \mathrm{c} ; 2017$ ) or by brief treatment with ionomycin and subsequent exposure to 6-dimethylaminopurine (6-DMAP) and/or cycloheximide and/or $R$-roscovitine (Samiec and Skrzyszowska, 2010 b, 2012 a; An et al., 2019). In pigs, to induce oocyte activation, a brief treatment with thimerosal, followed by incubation in the presence of dithiothreitol (DTT), is applied (Macháty et al., 1997; Tao et al., 2000). In contrast, some groups use N,N,N',N'-tetrakis-(2-pyridylmethyl)ethane-1,2-diamine (TPEN; a $\mathrm{Zn}^{2+}$ chelator) to decrease the level of available $\mathrm{Zn}^{2+}$ ions, which are responsible for maintaining meiotic arrest of pig oocytes at the MII stage (Suzuki et al., 2010; Lee et al., 2015). Moreover, activation of porcine nucleartransferred oocytes is evoked by biological stimuli (i.e., sperm-inherited proteins triggering intraooplasmic calcium oscillations) that have been introduced through 
electrofusion of reconstructed pig oocytes with xenogeneic cytoplasts (the so-called zygoplasts) isolated from in vivo-fertilized rabbit zygotes. The above-mentioned strategy of biological or pseudophysiological transcomplementary activation of porcine SCNT-derived oocytes, which is accomplished in calcium-depleted extracellular environment, has been developed and optimized by Polish research group from the National Research Institute of Animal Production in Balice near Kraków (Samiec et al., 2012; Samiec and Skrzyszowska, 2014). Reconstituted embryos are cultured in vitro until blastocyst formation, usually 5-7 days. Subsequently, the embryos are transferred into recipient females. In cattle, embryo transfer is performed non-surgically, while in small ruminants, reconstructed embryos are often transferred surgically or by endoscopic means. In contrast, porcine reconstructed embryos are transferred into the oviduct of surrogates immediately after activation (at 1-cell stage) (Niemann and Lucas-Hahn, 2012; Shufaro and Reubinoff, 2017), However, some groups transfer pig cloned embryos at the blastocyst stage (Lagutina et al., 2006; Li et al., 2009).

Table 1. Recent improvements in SCNT procedure

\begin{tabular}{|c|c|c|}
\hline $\begin{array}{c}\text { SCNT step } \\
\text { Improvement }\end{array}$ & Optimized condition & References \\
\hline 1 & 2 & 3 \\
\hline $\begin{array}{l}\text { Donor cell type selection } \\
\text { Proper selection of a donor } \\
\text { cell type }\end{array}$ & $\begin{array}{l}\text { Selection of nuclear donor cells with easy } \\
\text { retrieval, well-defined provenance, lack of } \\
\text { DNA aneuploidy or long telomeres and high } \\
\text { telomerase activity such as mesenchymal } \\
\text { stem cells (MSCs), cumulus cells surround- } \\
\text { ing mature oocytes or foetal/adult fibroblast } \\
\text { cells for its ability to reverse cellular aging to } \\
\text { increase efficiency of generating SCNT-de- } \\
\text { rived blastocysts and maintain full-term and } \\
\text { healthy postnatal development for the clones }\end{array}$ & $\begin{array}{l}\text { Batchelder et al. (2005) } \\
\text { Li et al. }(2013) \\
\text { Opiela et al. }(2013,2017) \\
\text { Rakha (2015) } \\
\text { Olivera et al. }(2019)\end{array}$ \\
\hline $\begin{array}{l}\text { Donor cell preparation } \\
\text { Modification of epigenetic } \\
\text { markers in nuclear donor } \\
\text { cells }\end{array}$ & $\begin{array}{l}\text { Treatment of ex vivo expanded differentiated } \\
\text { somatic cells or undifferentiated MSCs with } \\
\text { histone deacetylase inhibitors (HDACi) (e.g. } \\
\text { TSA, VPA) and/or with DNA methyltrans- } \\
\text { ferase inhibitors (DNMTi) (e.g. 5-aza-2'-de- } \\
\text { oxycytidine) to increase histone acetylation } \\
\text { and decrease DNA methylation levels of do- } \\
\text { nor cell nuclei to improve developmental ca- } \\
\text { pacities and/or quality parameters of cloned } \\
\text { embryos }\end{array}$ & $\begin{array}{l}\text { Enright et al. (2003) } \\
\text { Saini et al. (2006) } \\
\text { Samiec et al. }(2015,2019)\end{array}$ \\
\hline $\begin{array}{l}\text { Donor cell preparation } \\
\text { Nuclear remodeling }\end{array}$ & $\begin{array}{l}\text { A) Permeabilization of donor cell plasma } \\
\text { membranes and subsequent incubation of } \\
\text { permeabilized cells in a mitotic extract con- } \\
\text { taining an ATP-regenerating system extract } \\
\text { to elicit chromosome condensation and pro- } \\
\text { mote nuclear components removal } \\
\text { B) Protaminization of somatic cell nuclei - } \\
\text { conversion of interphase somatic nuclei into } \\
\text { "spermatid like" structures by transfection } \\
\text { with human protamine } 1 \text { gene (pPrm-1RFP) }\end{array}$ & Iuso et al. (2015) \\
\hline
\end{tabular}


Table 1 - contd.

\begin{tabular}{|c|c|c|}
\hline 1 & 2 & 3 \\
\hline $\begin{array}{l}\text { Recipient oocyte prepara- } \\
\text { tion } \\
\text { Modification of epigenetic } \\
\text { markers in nuclear recipi- } \\
\text { ent cells }\end{array}$ & $\begin{array}{l}\text { HDACi- or DNMTi-mediated epigenomic } \\
\text { transformation of in vitro maturing nuclear } \\
\text { recipient oocytes to improve epigenetic re- } \\
\text { programmability of somatic cell nuclei in } \\
\text { developing cloned embryos and thereby en- } \\
\text { hance their in vitro developmental capabili- } \\
\text { ties to reach the blastocyst stage }\end{array}$ & $\begin{array}{l}\text { Samiec and Skrzysz } \\
\text { (2012 b) } \\
\text { Wang et al. (2018) } \\
\text { Gupta et al. (2019) }\end{array}$ \\
\hline
\end{tabular}

Recipient oocyte preparation

Demecolcine-assisted enucleation

Recipient oocyte preparation

Addition of complimentary cytoplasm

Oocyte activation Sperm-mediated activation

Embryo reconstruction Serial nuclear transfer
Treatment of MII oocytes with demecolcine Iuso et al. (2013) to produce a membrane protrusion with chromosomes and straight enucleation without any chemical or physical aid to avoid UVrelated damages, especially in large animals where the MII plate is hardly detectable due to the high lipid content in the cytoplasm and harmful UV exposure usually is applied

Cytoplasm injection cloning technology Xu et al. (2019)

(CICT) via which the cytoplasmic volume of an enucleated oocyte is restored by injecting Song et al. (2019) $30 \%$ of the cytoplasm of a donor oocyte to increase the quality of recipient oocytes

A) In vitro fertilization of zona-intact oocytes. Schurmann et al. (2006)

Next, removal of zona pellucida followed by staining of fertilized oocytes with Hoechst 33342 and mechanical removal of both male and female chromatin. Then, fusion of the enucleated pre-activated cytoplasts with donor cells. B) Biological or pseudophysiological transcomplementary activation of nuclear- Samiec et al. (2012) transferred oocytes (in $\mathrm{Ca}^{2+}$-free environment) prompted by transcytoplasmic stimuli (i.e., sperm-inherited proteins triggering intraooplasmic calcium oscillations) that have been deposited and accumulated in nuclear recipient ooplasm through electrofusion of reconstructed oocytes with foreign species (xenogeneic) cytoplasts (the so-called zygoplasts) isolated from in vivo-fertilized zygotes. C) Development and optimization of novel technique of chimaeric somatic cell cloning, in which the single enucleated blastomeres Samiec and Skrzyszowska (the so-called blastoplasts) of 2-cell stage (2014) embryos (originating from in vivo-fertilized zygotes) provide a source of recipient cells for transgenic somatic cell nuclei.

Skrzyszowska et al. (2006)

Transfer of metaphase arrested donor cells to Ono et al. (2001) enucleated MII oocytes followed by artificial Li et al. (2002) activation. Transfer of the resultant MII apparatus to enucleated fertilized 1-cell embryos. In vitro culture of the constructed embryos to the blastocyst stage and then transfer to 
Table 1 - contd.

\begin{tabular}{c|c|c}
\hline 1 & 2 & 3 \\
\hline \multicolumn{2}{|c|}{ pseudo pregnant females or blastomeres from }
\end{tabular}

reconstructed morulae are transferred into the perivitelline space of the enucleated oocytes.

In vitro culture of cloned Treatment of activated nuclear-transferred Kishigami et al. (2006)

embryos oocytes and in vitro cultured cloned embryos (immediately after activation of nuclear- Gómez et al. (2012)

Treatment of cloned embryos with $\mathrm{HDAC} i$ transferred oocytes) with HDCAi and/or DNMTi to improve the efficiency of generat- Jin et al. $(2015,2018)$ ing SCNT-derived blastocysts. HDACi and/ or DNMTi can facilitate/expedite epigenetic Skrzyszowska and Samiec reprogramming modifications during the ac- (2020) tivation and post-activation culture of reconstructed oocytes.

In vitro culture of cloned embryos

Co-culture with parthenotes

Co-culture of embryos to create a microenvi-
ronment through secretion of autocrine and paracrine factors that can support and improve the embryos' development when compared to the embryos cultured individually.

In vitro culture of cloned embryos

Placing more than one zona-free embryos in Boiani et al. (2003) the same well in order to compensate reprogramming deficiencies through the interac- Buemo et al. (2016) tion between blastomeres.

Cloned embryo preparation Downregulation of Xist Deletion of Xist on the active X chromosome Inoue et al. (2010) in SCNT embryos by cytoplasmic injection expression with short interference RNA (siRNA) of Xist siRNA to improve their gene expres- Yang et al. (2019) sion patterns and developmental ability in vivo.

\section{Handmade cloning. Alternative for micromanipulator-based cloning}

The classic technique of SCNT is carried out using a micromanipulator operated by highly qualified personnel. However, Vajta et al. (2001) invented handmade cloning (HMC) - an alternative, simpler and more affordable technique for somatic cloning which does not require using a micromanipulator. In HMC, prior to the oocyte enucleation step, in vitro maturated oocytes are subjected to zona pellucida removal. Afterwards, a brief treatment with demecolcine, which produces membrane protrusions that contain condensed chromosomes, is employed. Then, protrusion cone-oriented enucleation is performed using sharp blades for bisection under a stereomicroscope. Enucleation results in two semi-cytoplasts, which are exposed to phytohemagglutinin which helps in attachment of donor cells to cytoplasts. Finally, reconstructed semi-embryos are fused either by single-step electrofusion or two-step electrofusion. HMC shows similar or even superior birth rates to those achieved with a micromanipulator (Verma et al., 2015). Since the first attempt, many studies have investigated HMC, which has especially spread to application with large animals: cattle (Tecirlioglu et al., 2003), horses (Lagutina et al., 2005), pigs (Zhang et al., 2012) and sheep (Zhang et al., 2013), as well as wild animals (Priya et al., 2014). 
However, there are certain complications limiting the use of HMC including automation of the technique, zona-free oocytes/embryos, and usage of heterogeneous cytoplasm in HMC. Still, there is lack of integration of the individual steps into a production line. Zona-free oocytes, cytoplasts, and reconstructed embryos can attach to each other (Vajta, 2007; Mahdi and Fakhrisadat, 2012). In spite of these challenges, Vajta et al. (2000) made some effort to develop the Well-of-the-Well (WOW) system providing three dimensional blastomere arrangement in zona-free embryos, or microchannels in which almost all the steps required for HMC can be performed (Vajta et al., 2005). Some drawbacks exist, like occurrence of gas bubbles in the channels during incubation, which causes bad passage of solution and deformation of the embryos. Unfortunately, efforts to overcome existing drawbacks are sparse (Verma et al., 2015). One practical problem and concern with HMC might be the use of heterogenous cytoplasm. Two hemi-cytoplasts from two individual oocytes are used for one cloned embryo production, resulting in three different sources of mitochondria (including donor cell). However, so far, no experimental or practical drawbacks of such heteroplasmy have been reported (Vajta, 2007; Jena and Malakar, 2018).

\section{Selected biological and molecular aspects of SCNT}

Normal fertilization vs. SCNT

Fertilization and the early cleavage stages are associated with massive epigenetic reprogramming of the paternal and maternal chromatin and are initiated by maternal RNA and proteins, accumulated during oogenesis and the final stages of oocyte maturation (Schultz, 1993). Fertilization is the union of sperm nucleus (1n chromosomal content), of paternal origin, with an oocyte nucleus (1n), of maternal origin. Sperm chromatin is highly compacted with protamines in place of histones whereas oocyte chromatin is arrested at MII and loosely compacted into nucleosomal arrays. These chromatin sets are remodeled in the zygote and early-cleavage-stage embryo by ooplasmic factors, which is coordinated by high level of maturation promoting factor (MPF) present in MII oocyte (Mann and Bartolomei, 2002). The incorporated sperm nucleus undergoes nuclear envelope breakdown (NEBD), protamines are substituted with histones, chromatin decondenses, and paternal pronuclear is formed. Upon fertilization, sperm-borne phospholipase C zeta1 (PLC- $\zeta 1$ ) induces oocyte activation through calcium oscillation and MPF breakdown which triggers oocyte to exit M phase and the developmental program (Saunders et al., 2002). Chromatin of maternal oocyte proceeds through the second meiotic division and maternal pronucleus is formed. DNA synthesis and transcription then occur asynchronously within the individual maternal and paternal pronuclei (Mann and Bartolomei, 2002).

In the somatic cloning procedure, the nucleus at G0/G1 (with $2 \mathrm{n}$ chromosomal content) is introduced by fusion or microinjection into nonactivated, enucleated MIIarrested unfertilized oocyte. Somatic cell is exposed to high level of MPF activity in the ooplasm that results in NEBD, subsequent premature chromosome condensation (PCC). PCC appears to be required for reprogramming, as the subsequent development of SCNT embryos is severely compromised without PCC (Kim et al., 2002). During PCC, most chromatin-bound proteins, including transcription factors (TFs), 
dissociate from the genome. As a result, donor cell chromatin is more accessible to oocyte factors involved in reprogramming and DNA synthesis. PCC can be stably maintained for hours until reconstructed oocytes are activated. Following oocyte activation, MPF decline, chromatin decondenses and pronuclei (PN) are formed (Mann and Bartolomei, 2002; Kim et al., 2002; Choi and Campbell, 2010). The PN in SCNT embryos is called pseudo-pronucleus (PPN). This is achieved through nuclear expansion, during which PPN incorporates a large amount of maternal proteins (Prather et al., 2000). Consequently, drastic changes in chromatin structure and protein association take place during this process (Matoba and Zhang, 2018).

\section{Molecular aspects of somatic cloning}

During the somatic cloning procedure, the fully differentiated somatic nucleus requires the erasure or reprogramming of epigenetic imprints on DNA by ooplasm factors, in order to restore the totipotency and reset back the somatic nuclei to zygotic patterns. This change, which may affect the subsequent gene expression pattern, is generally termed nuclear reprogramming. Throughout nuclear reprogramming, pluripotency genes are switched off and tissue-specific genes are up-regulated and need to be down-regulated to achieve a totipotent state (Kim et al., 2002; Mann and Bartolomei, 2002; Tian et al., 2003; Niemann et al., 2008).

One of the crucial aspects influencing the success of SCNT is nuclear chromatin remodeling allowing access of oocyte-specific factors and reprogramming of the donor nucleus (Mitalipov and Wolf, 2009). Nuclear remodeling is defined as a change in chromatin structure. It is known to alter the pattern of genes that are to be transcribed, known as nuclear reprogramming. Remodeling refers to the structural rearrangement of the chromatin and DNA, while reprogramming is the consequence of those physical changes (Niemann, 2016; Gouveia et al., 2020). Current opinion is that incomplete and inappropriate epigenetic remodeling and reprogramming of the somatic nucleus might be the principal cause of the extremely high losses during embryonic and fetal development and variety of abnormalities seen in cloned animals (Rideout et al., 2001; Mann and Bartolomei, 2002). Chromatin of the somatic cell is tightly associated with heterochromatin binding proteins and histones (Strahl and Allis, 2000; Tamada and Kikyo, 2004). Histone acetylation by histone acetyltransferase (HAT) leads to activation of gene transcription, whereas histone deacetylation by histone deacetylase (HDAC) promotes gene inactivation (Sun et al., 2003). Following fertilization, histone acetylation, such as histone $\mathrm{H} 3$ acetylation, occurs and allows the appropriate expression of genes related to early embryonic development. However, in SCNT, histone acetylation marks decrease and gradually disappear. For example, Lys9 acetylation of $\mathrm{H} 3$ (H3K9ac) at the zygotic genome activation (ZGA) stage and H3K14ac at the blastocyst stage (Wang et al., 2020). Increasing histone acetylation levels, especially $\mathrm{H} 3 \mathrm{~K} 9 \mathrm{ac}$ and $\mathrm{H} 3 \mathrm{~K} 14 \mathrm{ac}$, through treatment of ex vivo expanded nuclear donor cells and/or in vitro maturing nuclear recipient oocytes and/ or in vitro cultured SCNT-derived embryos with the histone deacetylase inhibitors (HDACi) (e.g., trichostatin A (TSA) or valproic acid (VPA)) enhances SCNT-mediated nuclear reprogramming, and thus, improves gene expression levels in mammalian cloned embryos (Kishigami et al., 2006; Costa-Borges et al., 2010; Lee et al., 
2010 b; Gómez et al., 2012; Jin et al., 2018). Analogous enhancements in incidence of epigenetic reprogramming and improvements in transcriptional activities of genes in developing cloned embryos are affected by decreasing DNA methylation levels through exposure of in vitro cultured nuclear donor cells and/or nuclear recipient oocytes and/or SCNT-derived embryos to DNA methyltransferase inhibitors (DNMTi) (e.g., 5-aza-2'-deoxycytidine (5-aza-dC)) (Enright et al., 2003; Gómez et al., 2012; Wu et al., 2019). Finally, such HDACi- and/or DNMTi-dependent epigenomic modulation of nuclear donor cells, nuclear recipient cells or activated nuclear-transferred oocytes results in not only increasing in vitro and/or in vivo developmental capabilities of cloned embryos but also improving their cytological and molecular qualities (Samiec and Skrzyszowska, 2012 b; Samiec et al., 2015, 2019; Opiela et al., 2017; Guo et al., 2018; Wang et al., 2018; Gupta et al., 2019). Histone methylation may also play an important role in somatic cell reprogramming. Generally, methylation of $\mathrm{H} 3 \mathrm{~K} 4, \mathrm{H} 3 \mathrm{~K} 36$ and $\mathrm{H} 3 \mathrm{~K} 79$ is related with activation of gene transcription, whereas H3K9, H3K27 and H4K20 methylation mainly inhibits gene expression (Cao et al., 2015). The most typical modifications are of H3 Lys4 (H3K4me3) and H3k27me3. During SCNT-mediated reprogramming, H3K4me3 level decreases and H3K27me3 level increases (Cao et al., 2015; Zhou et al., 2019; Wang et al., 2020). Another modification relevant in reprogramming is histone $\mathrm{H} 3$ lysine 9 trimethylation (H3K9me3). Matoba et al. (2014) found that H3K9me3 of the somatic nucleus is the major barrier of nuclear reprogramming and its incomplete demethylation in cloned embryos inhibits their development. A reprogramming strategy for improving cloning efficiency can be depletion of $\mathrm{H} 3 \mathrm{~K} 9 \mathrm{me} 3$ by injection of $\mathrm{Kdm} 4 \mathrm{mRNA}$ into SCNT embryos (Matoba et al., 2014; Liu et al., 2018).

The initial transcriptional activity of the donor nucleus is likely controlled predominantly by the egg cytoplasm. Upon SCNT, donor cell histones are rapidly replaced by maternally-stored histones. This histone replacement appears to be critical for successful reprogramming (Matoba and Zhang, 2018). Early reports demonstrated that human or Xenopus nuclei injected to Xenopus oocyte lose more than $85 \%$ nuclear proteins, and simultaneously incorporate a substantial amount of oocyte protein (Gurdon et al., 1979). Kikyo et al. (2000) showed that nonhistone nuclear proteins are selectively released (e.g., TATA binding protein) from, or incorporated into, somatic chromatin in oocyte by a chromatin remodeling protein complex. Also, global release and uptake of linker histone $\mathrm{H} 1$ is another challenge for the donor nuclei during the nuclear reprogramming. Histone subunits are linked together by histone H1, which makes up the nucleosome (Tamada and Kikyo, 2004). In mice, protein exchange after SCNT includes the histone variants H1FOO and MacroH2A. When a somatic cell nucleus is introduced into the ooplasm, an oocyte-specific alternative of histone H1, namely H1FOO, quickly replaces histone H1 (Gao et al., 2004). $\mathrm{MacroH} 2 \mathrm{~A}$, which is enriched in repressive chromatin, is eliminated from the donor somatic nucleus after SCNT, then at the morula stage of embryo development, and is re-established and accumulates in the chromatin as in normally fertilized embryo (Chang et al., 2010). In the event of a delayed change of H1FOO to somatic H1, macroH2A expression before the endogenous activation contributes to incomplete SCNT-mediated nuclear reprogramming (Gao et al., 2004; Chang et al., 2010). Be- 
sides the exchange of $\mathrm{H} 1$ and $\mathrm{MacroH} 2 \mathrm{~A}$, oocyte stored histone $\mathrm{H} 3$ variants $(\mathrm{H} 3.1$, $\mathrm{H} 3.2$, and H3.3), as well as H2AFX, are incorporated into the donor nucleus (Nashun et al., 2011).

The position of nucleosomes is regulated by chromatin remodeling factors and play an important role in regulating DNA access to transcription factors (Matoba and Zhang, 2018). Recently, Djekidel et al. (2018) analyzed chromatin accessibility site profile of 1-cell SCNT embryo, namely DNase I hypersensitive site (DHS). It was found that SCNT chromatin showed drastic loss of DNase I hypersensitive sites (DHSs) of the somatic donor cells concurrent with the appearance of some zygotespecific DHSs. Specific DHSs of donor somatic cells fail to be reprogrammed to those of embryos, which prevents the binding of chromatin remodeling factors to regulate gene expression in cloned embryos. Loss of donor cell DHSs correlates with suppression of somatic transcription program (Djekidel et al., 2018).

\section{Telomeres and lifespan of cloned animals}

Since the cloning of Dolly the sheep, much attention has been given to the issue of telomere length, prompting the speculation that cloning from adult cells could result in offspring with shorter telomeres, premature onset of aging and reduced lifespan.

Telomeres are the ends of chromosomes composed of repetitive DNA sequences (5'-TTAGGG-3') and specific proteins forming together the nucleoprotein complex. Telomeres are crucial in maintaining the integrity of the entire genome, replication, segregation of the chromosomes during mitosis and preventing end-to-end fusions and degradation of the chromosome ends. Changes in telomere length are closely related to aging and cancer. To maintain the natural length of telomeric DNA, the specialized reverse transcriptase-telomerase is required (Blackburn, 1991). In the absence of telomerase activity, telomeres shorten progressively as a consequence of incomplete DNA replication of each cell cycle. Telomere shortening correlates with cellular aging of human fibroblasts in vitro (Harley et al., 1990). Some cells isolated from older individuals have a shorter replicative lifespan in culture and shorter telomeric DNA, which has been taken as evidence for a role of telomere shortening in vitro (Hastie et al., 1990).

Telomere length analyses in cloned animals have shown divergent results. In cloning Dolly the sheep, genetic material was transferred to enucleated oocytes from adult mammary epithelial cells, which had exhibited a decrease in telomere length and telomerase activity. Dolly's chromosomes had telomere lengths shorter by approximately $20 \%$ when compared with age-matched, naturally bred counterparts (Shiels et al., 1999). Alexander et al. (2007) revealed that telomeres in sheep clones were shortened compared with age-matched controls since offspring derived by sexual reproduction from clones had normal telomere length. In contrast, calves cloned from a 10-year-old bull had similar or even shorter telomeres than the donor animal, seemingly depending on the cell type investigated (Kato et al., 2000). Moreover, other experiments reported normal telomere lengths and restoration of telomerase activity in cloned cattle embryos (Tian et al., 2000; Betts et al., 2001). In 2000, Lanza et al. used senescent bovine fibroblasts with shortened telomeres as nuclear donors 
in somatic cloning. The experiment revealed that donor cells resurrected after NT exhibited even longer telomeres than age-matched controls and an increased proliferative lifespan in culture.

\section{Nuclear remodeling and mitochondrial DNA (mtDNA) heteroplasmy}

Only ooplasm has the ability to reprogram somatic nuclei. Reprogramming of the somatic cell nucleus constitutes an excellent model for the analysis of gene expression, chromatin remodeling at the early stage of embryonic development and mechanisms involved in epigenetic reprogramming (Ambrosi and Rasmussen, 2005). Also, one of the important results showing the potential of SCNT in basic research was discovering a specific telomere length programmed at the morula-blastocyst transition in bovine and mouse embryos (Schaetzlein et al., 2004), investigation of telomere length regulation and genes involved in the maintenance of pluripotency such as octamer-binding transcription factor 4 gene (OCT4) (Nowak-Imialek et al., 2011).

Moreover, from the molecular point of view, cloning techniques utilizing nuclear transfer to the enucleated oocyte do not strictly produce an individual with DNA compositions $100 \%$ identical to those of the donor nucleus. Not only recipient ooplasm but also cytoplasm of nuclear donor cell carries its own mitochondrial compartments and thereby mtDNA fractions. Therefore, reconstruction of enucleated oocytes by SCNT contributes to generation of nuclear-ooplasmic hybrids that are characterized by the hybridization of heteroplasmic mitochondrial compartments inherited from both nuclear donor cells and nuclear recipient oocytes. This phenomenon is designated as mtDNA heteroplasmy (Samiec, 2005 a, b; Samiec and Skrzyszowska, 2018 b). Although a cloned individual has the same genomic DNA as the donor, the cells will possess from 41 to $100 \%$ of the total cellular mtDNA from abattoir-derived oocytes and female clones will transmit this heteroplasmic mtDNA to their offspring (Tong et al., 2002). What is more, random mtDNA mutation in the clone may still occur and there is a likelihood for increasing this phenomenon due to the culture conditions of the donor cell, the oocyte and the resulting embryo (Tong et al., 2002). Finally, the clone is affected by different environments which can have an impact on further development. Compared with nuclear reprogramming, very few studies have focused on problems related to the association between mitochondria and nuclear reprogramming (Steinborn et al., 2002; Tong et al., 2002). Czernik et al. (2019) presented a comprehensive review about the effects of mitochondrial defects on the SCNT-derived embryo/foetus. Therefore, the issue of mtDNA heteroplasmy of clones is still being debated and investigated. Interestingly, researchers have tried to avoid the problem of mtDNA heteroplasmy. Lee et al. (2010 a) produced cloned lambs using mitochondria-depleted cells. Also, Choi et al. (2014) overcame the problem of mtDNA heteroplasmy and produced $100 \%$ genetically identical individuals by using host-derived oocytes from the same animal that supplied the nuclear donor cells. Recently, Srirattana and St. John (2017) successfully generated SCNT embryos by using mtDNA-depleted donor cells with additional treatment of cloned embryos with reprogramming modifier TSA, resulting in improved development of SCNT-derived embryos. 


\section{Donor cells}

In mammals, around 200 types of somatic cells have been characterized and classified (Oback and Wells, 2002). Less than 5\% of these cells have been used as sources of nuclei for cloning domestic and laboratory animals, e.g., cumulus cells (Kato et al., 2000), embryonic cells (Campbell et al., 1996 b), fibroblasts (Cibelli et al., 1998), germ cells (Yamazaki et al., 2005), granulosa cells (Poleajeva et al., 2000), mammary gland cells (Wilmut et al., 1997), oviductal cells (Kato et al., 2000), leukocytes (Galli et al., 1999), liver cells (Kato et al., 2000), kidney cells (Richter et al., 2012), and mesenchymal stem cells (MSCs) (Samiec et al., 2019; Opiela et al., 2017), neural stem cells (Mizutani et al., 2006), bone marrow stem cells (Li et al., 2013; Olivera et al., 2018), skin-derived precursor cells (Xiao et al., 2016), spermatogonial stem cells (Lee et al., 2019) and induced pluripotent stem cells (iPSCs) (Olivera et al., 2016). All of them supported development to the blastocyst stage, while many also failed to generate viable offspring (Oback and Wells, 2002; Li et al., 2013; Opiela and Samiec, 2013; Rakha, 2015; Xiao et al., 2016; Olivera et al., 2016, 2018; Lee et al., 2010 b, 2019). Usually, the developmental potential of cloned embryos receiving terminally differentiated donor cell nuclei is considerably lower than that noticed for their counterparts reconstructed with either partially differentiated donor cell nuclei (Li et al., 2003) or undifferentiated MSCs (Samiec et al., 2015, 2019; Opiela et al., 2017; Olivera et al., 2018) and iPSCs (Olivera et al., 2016). Indeed, different cell types do not exhibit the same potential for reprogramming in the oocyte cytoplasm. Each cell type has its unique epigenetic status characteristic of the type of tissue from which it is derived. Still, it is not clear why cells from some tissues are better nuclear donors than those from others (Mann and Bartolomei, 2002; Oback and Wells, 2002).

The cloning procedure is affected by several donor factors, including age, cell origin, cell cycle phase, telomere length, telomerase activity or the ability to differentiate into any type of tissue (Rakha, 2015). The first mammal was cloned using somatic cells derived from a cell line derived from sheep mammary gland cells, which probably entered the G0/G1 phase of the cell cycle (Wilmut et al., 1997). Initially, the cells most preferred in somatic cloning were granulosa cells naturally existing at the G0/G1 stage. These donor cells have been reported to support the highest frequency of cloned births. However, only female offspring were produced (Wakayama et al., 1998). Boquest et al. (1999) stated that donor cells at the G0/G1 stage of the cell cycle transferred into metaphase II stage oocytes are susceptible to proper reprogramming by the oocyte cytoplasm and support development of the reconstructed embryo. Next to granulosa cells, fibroblasts are the most commonly used cells, after being starved or cultured to confluence to reach the G0/G1 phase, and representing a convenient nuclei source that can be easily obtained by primary culture of skin pieces and which are not demanding for culture in vitro.

\section{Remarkable achievements with different sources of donor cells}

Until now, a large variety of somatic cell types have been successfully exploited in SCNT as nuclear donors. In most scientific reports, freshly collected or cultured cells have been utilized. Meanwhile, in some research into somatic cloning, well- 
preserved tissues or cells have been used, suggesting that these materials cryopreserved postmortem without cryoprotectant can allow resurrection of the postmortem animal by SCNT (Wakayama et al., 2008; Hoshino et al., 2009; Kato et al., 2009). Indeed, an essential requirement for cloning is the availability of soft or alternatively well-preserved tissue with identifiable nuclei (Kato et al., 2009; Loi et al., 2014). Additionally, some results clearly indicate that even the viability of donor cells might not be a prerequisite for production of SCNT cloned embryos/animals but only their intact nuclear materials (DNA), which can serve as the basis of a nucleus formation. Loi et al. (2002) demonstrated that non-viable sheep cells that were artificially heat denatured at $55^{\circ} \mathrm{C}$ or $75^{\circ} \mathrm{C}$ developed to full term after injection into enucleated matured oocytes. In recent years, other spectacular achievements have been made, such as cloning of mice from cells deriving from the skin tissue of a dead individual frozen without a cryoprotectant at $-20^{\circ} \mathrm{C}$ for 16 years (Wakayama et al., 2008) or of a bull from cells obtained from testicles collected from a dead animal and frozen without a cryoprotectant at $-80^{\circ} \mathrm{C}$ for 10 years (Hoshino et al., 2009). In turn, Saeki et al. (2014) managed to obtain live cells from tissue fragments taken from the heart, ear, liver, kidneys and spleen that were held for 1 to 15 days at $4^{\circ} \mathrm{C}$. Even cloning with cells recovered from beef purchased in a butcher's shop several days after slaughter (Adams et al., 2004; Arat et al., 2005) turned out to be equally spectacular, which indicates that even if an animal is dead but the karyoplast has not been damaged, the cells can be used for cloning. It creates the possibility of reproduction even if an animal is dead or extinct but whose tissues have been preserved in a frozen state. Clones were also obtained from epithelial cells derived from a vaginal smear (Kuwayama et al., 2017), cells isolated from urine (Madheshiya et al., 2015), or somatic cells isolated from thawed buffalo semen (Selokar et al., 2016). Attempts have been made to use freeze-dried somatic cells (Loi et al., 2008; Ono et al., 2008), which in the future may facilitate the long-term storage of somatic cells even at room temperature, which would be an excellent alternative to storing biological materials in liquid nitrogen or a freezer.

One of the most spectacular achievements was the restoration of cell nuclei from an extinct species, namely a 14,000-15,000 years old mammoth, which was found in the frozen and intact state. Kato et al. (2009) recovered cell nucleus-like structures from skin and muscle tissues and injected them into enucleated mouse oocytes by SCNT. More than half of the oocytes were able to survive. In 2014, Loi et al. based on the recovery of nuclei in 2009, presented two possible strategies and prospects to resurrect a mammoth by applying one of two methods, namely "Synthetic" genome assembly and nuclear transfer or "Canonical" Interspecies Somatic Cell Nuclear Transfer (iSCNT). The first method involves mammoth genome synthesis (genomic and mtDNA had already been sequenced in 2008), followed by allocation into individual chromosomes using the elephant genotype and karyotype $(2 \mathrm{n}=56)$ as a guide. Notably, the elephant is the most closely related animal and was proposed to be both an oocyte donor as well as a surrogate mother in SCNT of the mammoth. Next, the formidable task is to arrange the DNA into respective chromosomes with vital sequences required for DNA replication and segregation in mitosis (telomeres, centrosomes), but especially the allocation of the centrosomes, which are essential for 
cell division. Presumably, centrosomes could be obtained from elephant tissues and associated with the chromosome set but the difficulty would be to package and hold together the chromosomes and the centrosomes in the mammoth-unique structure. Then, electro-mediated fusion of artificial chromosomes along with the centrosome into an enucleated elephant oocyte could complete the procedure resulting in mammoth/elephant hybrid embryos. Given that the structure should also allow the transfer of the chromosomes/centriole into an egg, a synthetic lipid monolayer appears to be the most appropriate solution. Artificial membranes have been a reality for many years, and the state of the art is particularly advanced thanks to recent development in the production of artificial cells (Zagnoni, 2012; Loi et al., 2014). In theory, it is an interesting approach and vision of cloning, however, we cannot foresee how this "artificial" material could be involved in remodeling, epigenetic and transcriptional machinery in the oocyte. The second proposed method is Interspecific Somatic Cell Nuclear Transfer (iSCNT), in which the nucleus is taken from a target species and transplanted into an enucleated oocyte from a different species, which is a powerful tool in the conservation of endangered animals. However, this methodology results in the production of nuclear-cytoplasmic hybrids (Loi et al., 2011). The method proposed by Loi et al. (2014) would be the transfer of nuclei recovered by the Kato group into Asian elephant oocytes but unfortunately, until now, the availability of elephant oocytes is severely limited.

\section{Concluding remarks}

Since the first attempt, cloning animals by SCNT remains a fascinating biological problem. SCNT has grown into a technology with many potential applications including rescue of endangered animals, replication of superior farm animals, production of genetically engineered animals, creation of biomedical models, basic research, and medicine. Althrough SCNT requires a series of technically difficult steps to be accomplished, animal cloning has now been successfully applied in 24 different species. The current understanding of some molecular and biological aspects of SCNT has increased. Recent findings have revealed reprogramming barriers and prompted the development of methods to overcome such limits. A reprogramming strategy for improving cloning efficiency has been proposed including e.g., manipulation of epigenetic marks using histone deacetylase inhibitors. Improved cloning technology might extend many of the above-mentioned applications to their fullest potential.

\section{References}

A d a m s A.M., Pratt S.L., Gibbons J.R., Arat S., Res pes s D.S., S tice S.L. (2004). Production of a cloned calf using kidney cells obtained from a 48-hour cooled carcass. Reprod. Fert. Develop., 16: 133-292.

A lexander B., Coppola G., Perrault S.D., P eura T.T, B et t s D.H., King W.A. (2007). Telomere length status of somatic cell sheep clones and their offspring. Mol. Reprod. Dev., 74: 1525-1537.

A mbrosi D.J., Ras mus sen T.P. (2005). Reprogramming mediated by stem cell fusion. J. Cell. Mol. Med., 9: 320-330. 
An Q., Peng W., Cheng Y., Lu Z., Z hou C., Z hang Y., S u J. (2019). Melatonin supplementation during in vitro maturation of oocyte enhances subsequent development of bovine cloned embryos. J. Cell. Physiol., 234: 17370-17381.

Arat S., Bagis H., Odaman Mercan H., Dinnyes A. (2005). Cloned embryos can be produced using donor cells obtained from a 72-hour cooled carcass. Reprod. Fert. Develop., 17: 164-164.

Baguisi A., B ehboodi E., Melican D.T., Pollock J.S., Destrempes M.M., Cammus o C., Williams J.L., Nims S.D., Porter C.A., Midura P., Palacios M.J., Ayres S.L., D en niston R.S., Hayes M.L., Zi o mek C.A., Me a d e H.M., Go d ke R.A., Gavin W.G., Overström E.W., Ech elard Y. (1999). Production of goats by somatic cell nuclear transfer. Nat. Biotechnol., 17: 456-461.

B a t c h e ld e r C.A., H o ffert K.A., B e r tolin i M., M o y e r A.L., M a s o n J.B., P e t k o v S.G., F a m u la T.R., A n d e r s o n G.B. (2005). Effect of nuclear-donor cell lineage, type and cell donor on development of somatic cell nuclear transfer in cattle. Cloning Stem Cells, 4: 238-254.

B erg D.K., Li C., A s her G., Wells D.N., Oba ck B. (2007). Red deer cloned from antler stem cells and their differentiated progeny. Biol. Reprod., 77: 384-394.

Betts D., Bordignon V., Hill J., Winger Q., Westhusin M., S mith L., King W.A. (2001). Reprogramming of telomerase activity and rebuilding of telomere length in cloned cattle. Proc. Natl. Acad. Sci. USA., 98: 1077-1082.

B l a c kburn E.H. (1991). The structure and function of telomeres. Nature, 350: 569-573.

B o i a ni M., Eckartd S., L e u N.A., S chöler H.R., Mc La ughlin K.J. (2003). Pluripotency deficit in clones overcome by clone aggregation: epigenetic complementation? EMBO J., 22: 5304-5312.

B o que st C.A., D a y N.B., P r a the r S.R. (1999). Flow cytometric cell cycle analysis of cultured porcine fetal fibroblast cells. Biol. Reprod., 60: 1013-1019.

B u e m o C.P., G a m b in i A., Moro L.N., H ir i art M.I., F e rn and e z - M art in i R., Collas P., $\mathrm{S}$ a la mo ne D.F. (2016). Embryo aggregation in pig improves cloning efficiency and embryo quality. PLoS One, 11(2): e0146390.

C a m p b e 11 K.H., L o i P., O t a e gu i P.J., Wi 1 m u t I. (1996 a). Cell cycle co-ordination in embryo cloning by nuclear transfer. Rev. Reprod., 1: 40-46.

C a m p be 11 K.H., M c Wh ir J., R i t ch i e W.A., Wilm ut I. (1996 b). Sheep cloned by nuclear transfer from a cultured cell line. Nature, 380: 64-66.

Ca o Z., Li Y., Chen Z., Wang H., Zhang M., Zhou N., Wu R., Ling Y., Fang F., Li N., $\mathrm{Z}$ h a n g Y. (2015). Genome-wide dynamic profiling of histone methylation during nuclear transfermediated porcine somatic cell reprogramming. PLoS One, 10(12), e0144897.

Chang C.C., Ga o S., Sung L.Y., Corry G.N., Ma Y., Nagy Z.P., Tian X.C., R a s mus $\mathrm{s}$ e $\mathrm{n}$ T.P. (2010). Rapid elimination of the histone variant MacroH2A from somatic cell heterochromatin after nuclear transfer. Cell. Reprogram., 12: 43-53.

Chen Y., Xu Z.H.E., Liu A., Wang K., Mao W.W., Chu J.X., Lu Y., Fang Z.F., Shi Y.T., Yang Q.Z., Chen D.Y., Wang M.K., Li J.S., Huang S.L., Kong X.Y., Shi Y.Z., Wang Z.Q., X i a J.H., L ong Z.G., X u e Z.G., D ing W.X., S he ng H.Z. (2003). Embryonic stem cells generated by nuclear transfer of human somatic nuclei into rabbit oocytes. Cell Res., 13: 251-263.

Chesne P., A d en ot P.G., Vigliet t a C., B arat te M., B o u langer L., R en ard J.P. (2002). Cloned rabbits produced by nuclear transfer from adult somatic cells. Nat. Biotechnol., 20: 366-369.

Choi I., Ca m p bel1 K.H.S. (2010). Treatment of ovine oocytes with caffeine increases the accessibility of DNase I to the donor chromatin and reduces apoptosis in somatic cell nuclear transfer embryos. Reprod. Fert. Develop., 22: 1000-1014.

Choi Y.H., Love C.C., Chung Y.G., Varner D.D., Westhus in M.E., Burghardt R.C., Hinrichs K. (2002). Production of nuclear transfer horse embryos by Piezo-driven injection of somatic nuclei and activation with stallion sperm cytosolic extract. Biol. Reprod., 67: 561-567.

Choi Y.H., Ritthaler J., Hinrichs H. (2014). Production of a mitochondrial-DNA identical cloned foal using oocytes recovered from immature follicles of selected mares. Theriogenology, 82: $411-417$.

Cibelli J.B., Stice S.L., Golueke P.J., Kane J.J., Jerry J., Blackwell C., Ponce de 
L e ó n F.A., R o b 1 J.M. (1998) Cloned transgenic calves produced from nonquiescent fetal fibroblasts. Science, 280: 1256-1258.

Cost a - B orge s N., S a n ta l ó J., I báñ e z E. (2010). Comparison between the effects of valproic acid and trichostatin A on the in vitro development, blastocyst quality, and full-term development of mouse somatic cell nuclear transfer embryos. Cell. Reprogram., 12: 437-446.

Czernik M., A nzal o ne D.A., P a lazze s e L., O i k aw a M., P a s qua l in o L. (2019). Somatic cell nuclear transfer: failures, successes and the challenges ahead. Int. J. Dev. Biol., 63: 123-130.

Dalman A., Eftekhari - Yazdi P., Valojredi M.R., Shahverdi A., Gourabi H., Janz a m in E., F a kh eri R., S a d e g h i a n F., H a s a n i F. (2010). Synchronizing cell cycle of goat fibroblasts by serum starvation causes apoptosis. Reprod. Dom. Anim., 45: e46-53.

Djekidel M.N., In ou e A., Mat oba S., Suzuki T., Zhang C., Lu F., Jiang L., Zhang Y. (2018). Reprogramming of chromatin accessibility in somatic cell nuclear transfer is DNA replication independent. Cell. Reprogram., 23: 1939-1947.

Eggan K., A kutsu H., Hochedlinger K., Rideout W. 3rd, Yanagimachi R., Jae$\mathrm{n}$ is ch R. (2000). X-Chromosome inactivation in cloned mouse embryos. Science, 290: 15781581 .

Enright B.P., K ub ot a C., Yang X., Ti an X.C. (2003). Epigenetic characteristics and development of embryos cloned from donor cells treated by trichostatin A or 5-aza-2'-deoxycytidine. Biol. Reprod., 69: 896-901.

Folch J., Cocero M.J., Chesne P., Alabart J.L., Dominguez V., Cognie Y., Roche A., Fernández-Ari a s A., M artí J.I., S án c he z P., E c he g o y e n E., B e c ker s J.F., B on a stre A.S., Vig n o n X. (2009). First birth of an animal from an extinct subspecies (Capra pyrenaica pyrenaica) by cloning. Theriogenology, 71: 1026-1034.

Galli C., Duchi R., Mo or R.M., Lazzari G. (1999). Mammalian leukocytes contain all the genetic information necessary for the development of a new individual. Cloning, 1: 161-170.

Galli C., Lagutina I., Crotti G., Colleoni S., Turini P., Ponderato N., Duchi R., L a z z a ri G. (2003). A cloned horse born to its dam twin. Nature, 424: 635.

Gambini A., Mas erati M. (2018). A journey through horse cloning. Reprod. Fert. Develop., 30: $8-17$.

Ga o S., Chung Y.G., Parseghian M.H., King G.J., Adashi E.Y., Latham K.E. (2004). Rapid H1 linker histone transitions following fertilization or somatic cell nuclear transfer: Evidence for a uniform developmental program in mice. Dev. Biol., 266: 62-75.

Gó m e z M.C., P o p e E., H a r r i s R., M i k o t a S., D res s e r B.L. (2003). Development of in vitro matured, in vitro fertilized domestic cat embryos following cryopreservation, culture and transfer. Theriogenology, 60: 239-251.

Gómez M.C., Pope C.E., Giraldo A., Lyons L.A., Harris R.F., King A.L., Cole A., G o d k e R.A., D re s s e r B.L. (2004). Birth of African wildcat cloned kittens born from domestic cats. Cloning Stem Cells, 6: 247-258.

Gó m e z M.C., P o p e C.E., K u tn e r R.H., Ri c k s D.M., Ly on s L.A., Ru h e M.D., Du m a s C., Ly on s J., Ló pe z M., D res se r B.L., R e i s e r J. (2008). Nuclear transfer of sand cat cells into enucleated domestic cat oocytes is affected by cryopreservation of donor cells. Cloning Stem Cells, 4: 469-483.

Gó m e z M.C., B i an c a rd i M.N., J en kins J.A., D u ma s C., Galigu is J., Wang G., Earle P op e C. (2012). Scriptaid and 5-aza-2'deoxycytidine enhanced expression of pluripotent genes and in vitro developmental competence in interspecies black-footed cat cloned embryos. Reprod. Domest. Anim., 47 (Suppl 6): 130-135.

Gouveia C., Huyser C., Egli D., Pepper M.S. (2020). Lessons learned from somatic cell nuclear transfer. Int. J. Mol. Sci., 21: 2314.

G u o Z., L v L., L i u D., F u B. (2018). Effects of trichostatin A on pig SCNT blastocyst formation rate and cell number: A meta-analysis. Res. Vet. Sci., 117: 161-166.

Gupta M.K., He o Y.T., K i m D.K., Lee H.T., Uhm S.J. (2019). 5-Azacytidine improves the meiotic maturation and subsequent in vitro development of pig oocytes. Anim. Reprod. Sci., 208: 106118.

Gurdon J.B., Las key R.A., D e Robert is E.M., Partington G.A. (1979). Reprogramming of transplanted nuclei in amphibia. Int. Rev. Cytol. (Suppl.), 9: 161-178. 
H a r le y C.B., F u t c he r A.B., Gre i d e r C.W. (1990). Telomeres shorten during ageing of human fibroblasts. Nature, 345: 458-460.

Hastie N.D., Dempster M., Dunlop M.G., Thompson A.M., Green D.K., A 11 shire R.C. (1990). Telomere reduction in human colorectal carcinoma and with ageing. Nature, 346 : $866-868$.

H i 11 J.R. (2014). Incidence of abnormal offspring from cloning and other assisted reproductive technologies. Annu. Rev. Anim. Biosci., 2: 16.1-16.15.

Hoshino Y., Hayashi N., Taniguchi S., Kobayashi N., Sakai K., Otani T., Irita$\mathrm{n}$ i A., S a e k i K. (2009). Resurrection of a bull by cloning from organs frozen without cryoprotectant in a $-80^{\circ} \mathrm{C}$ freezer for a decade. PLoS One, 4(1): e4142.

Inoue K., Kohda T., Sugimoto M., Sado T., Ogonuki N., Matoba S., Shiura H., Ikeda R., Mochida K., Fujii T., Sawai K., Otte A.P., Tian X.C., Yang X., Ishino F., A b e K., Ogura A. (2010). Impeding Xist expression from the active X chromosome improves mouse somatic cell nuclear transfer. Science, 330: 496-499.

I u s o D., Czernik M., Za c ch in i F., P tak G., L o i P. (2013). A simplified approach for oocyte enucleation in mammalian cloning. Cell. Reprogram., 15: 490-494.

Iuso D., Czernik M., Toschi P., Fidanza A., Zacchini F., Feil R., Curtet S., Buchou T., Shiota H., Khochbin S., Ptak G.E., Loi P. (2015). Exogenous expression of human protamine 1 (hPrm1) remodels fibroblast nuclei into spermatid-like structures. Cell Rep., 13: $1765-1771$.

J e n a M.K., M a lakar D. (2018). Handmade cloning: a handy technique for reproductive cloning. J. Pharm. Sci. Res. 9: 1564-1568.

Jin J.X., Kang J.D., Li S., J in L., Z hu H.Y., Gu o Q., G a o Q.S., Yan C.G., Y in X.J. (2015). PXD101 significantly improves nuclear reprogramming and the in vitro developmental competence of porcine SCNT embryos. Biochem. Biophys. Res. Commun., 456: 156-161.

Jin L., Guo Q., Zhang G.L., Xing X.X., Xuan M.F., Luo Q.R., Luo Z.B., Wang J.X., Y in X.J., Kang J.D. (2018). The histone deacetylase inhibitor, CI994, improves nuclear reprogramming and in vitro developmental potential of cloned pig embryos. Cell. Reprogram., 20: 205-213.

K a to Y., Tani T., Ts un od a Y. (2000). Cloning of calves from various somatic cell types of male and female adult, newborn and fetal cows. J. Reprod. Fertil., 120: 231-237.

Kato H., Anzai M., Mitani T., Morita M., Nishiyama Y., Nakao A., Kondo K., Lazare v P.A., Oht a n i T., Shib at a Y., Iritan i A. (2009). Recovery of cell nuclei from 15,000 years old mammoth tissues and its injection into mouse enucleated matured oocytes. Proc. Jpn. Acad. Ser. B. Phys. Biol. Sci., 85: 240-247.

Kham manit R., Chantarku S., K it i y a n t Y., S a i khun J. (2008). Effect of serum starvation and chemical inhibitors on cell cycle synchronization of canine dermal fibroblasts. Theriogenology, 70: 27-34.

K i k y o N., Wa d e P.A., Gus ch in D., G e H., Wolffe A.P. (2000). Active remodeling of somatic nuclei in egg cytoplasm by the nucleosomal ATPase ISWI. Science, 289: 2360-2362.

K i m J.M., O g u r a A., N a g a t a M., A o k i F. (2002). Analysis of the mechanism for chromatin remodeling in embryos reconstructed by somatic nuclear transfer. Biol. Reprod., 67: 760-766.

K is higa m i S., M izut an i E., Oht a H., Hi k i ch i T., Thuan N.V., Wa ka y a m a S., B u i H.T., Wa k a y a m a T. (2006). Significant improvement of mouse cloning technique by treatment with trichostatin A after somatic nuclear transfer. Biochem. Biophys. Res. Commun., 340: 183-189.

K uw a y m a H., Ta n ab e Y., Wa k a y a m a T., K is hig a mi A. (2017). Birth of cloned mice from vaginal smear cells after somatic cell nuclear transfer. Theriogenology, 94: 79-85.

Lagutina I., Lazzari G., Duchi R., Colle oni S., Ponderato N., Turin P., Crotti G., Galli C. (2005). Somatic cell nuclear transfer in horses: effect of oocyte morphology, embryo reconstruction method and donor cell type. Reproduction, 130: 559-567.

L a gut in a I., L a z z a ri G., Ga 11 i C. (2006). Birth of cloned pigs from zona-free nuclear transfer blastocysts developed in vitro before transfer. Cloning Stem Cells, 8: 283-293.

Lanza R.P., Cibelli J.B., Blackwell C., Cristofalo V.J., Francis M.K., Baerlocher G.M., Mak J., Schertzer M., Chavez E.A., Sawyer N., Lansdorp P.M., We s t M.D. (2000). Extension of cell line lifespan and telomere length in animals cloned from senescent somatic cells. Science, 288: 665-669. 
Le e J.W., Wu S.C., Tian X.C., B arber M., Hoag land T., Ries en J., Lee K.H., Tu C.F., Cheng W.T., Yang X. (2003). Production of cloned pigs by whole-cell intracytoplasmic microinjection. Biol. Reprod., 69: 995-1001.

L e e B.C., Kim M.K., Jang G., Oh H.J., Yuda F., Kim H.J. (2005). Dogs cloned from adult somatic cells. Nature, 436: 641.

Le e J.H., P eters A., F isher P., B ow les E.J., S t John J.C., C a m p bell K.H. (2010). Generation of mtDNA homoplasmic cloned lambs. Cell. Reprogram., 12: 347-355.

L e e H.S., Yu X.F., B ang J.I., Cho S.J., D e b G.K., K i m B.W., K ong I.K. (2010 a). Enhanced histone acetylation in somatic cells induced by a histone deacetylase inhibitor improved inter-generic cloned leopard cat blastocysts. Theriogenology, 74: 1439-1449.

Le e S.L., Kang E.J., Ma eng G.H., K i m M.J., Park J.K., Kim T.S., Hy un S.H., Lee E.S., Rho G.J. (2010 b). Developmental ability of miniature pig embryos cloned with mesenchymal stem cells. J. Reprod. Dev., 56: 256-262.

Lee K., Davis A., Zhang L., Ryu J., Spate L.D., Park K.W., Samuel M.S., Wa1 ters E.M., Murphy C.N., Machaty Z., Prather R.S. (2015). Pig oocyte activation using a $\mathrm{Zn}^{2+}$ chelator, TPEN. Theriogenology, 84: 1024-1032.

L e e S.C., L e e H., O h K.B., Hw a ng I.S., Yang H., P a rk M.R., O c k S.A., W o o J.S., I m G.S., Hw ang S. (2017). Production and breeding of transgenic cloned pigs expressing human CD73. Dev. Reprod., 21: 157-165.

L e e J., L e e Y., L e e G.S., L e e S.T., L e e E. (2019). Comparative study of the developmental competence of cloned pig embryos derived from spermatogonial stem cells and fetal fibroblasts. Reprod. Domest. Anim., 54: 1258-1264.

Li J., Ch en D., H a n Z., Z hu Z., We n D., S u n Q., Li u Z., Wa ng M., L i a n L., D u J., Wa ng P. $\mathrm{Z}$ h a n $\mathrm{g}$ H. (2002). Serial nuclear transfer improves the development of interspecies reconstructed giant panda (Ailuropoda melanoleuca) embryos. Chin. Sci. Bull., 47: 467-469.

Li X., Li Z., J o un e a u A., Z h o u Q., R en ard J.P. (2003). Nuclear transfer: Progress and quandaries. Reprod. Biol. Endocrinol., 1: 84.

Li Z., S u n X., Chen J., Li u X., W is e ly S.M., Z hou Q., R e n ard J.P., Le no G.H., Eng e 1 hardt J.F. (2006). Cloned ferret produced by somatic cell nuclear transfer. Dev. Biol., 293: 439-448.

Li R., Murphy C.N., S pat e L., Wax D., I s o m C., Ri e ke A., Walt e r s E.M., S a mue 1 M., Prat h e r R.S. (2009). Production of piglets after cryopreservation of embryos using a centrifugation-based method for delipation without micromanipulation. Biol. Reprod., 80: 563-571.

L i Z., H e X., Ch e n L., S h i J., Z h o u R., X u W., L i u D., W u Z. (2013). Bone marrow mesenchymal stem cells are an attractive donor cell type for production of cloned pigs as well as genetically modified cloned pigs by somatic cell nuclear transfer. Cell. Reprogram., 15: 459-470.

Liu Z., Cai Y., Wang Y., Nie Y., Zhang C., Xu Y., Zhang X., Lu Y., Wang Z., Poo M., S u n Q. (2018). Cloning of macaque monkeys by somatic cell nuclear transfer. Cell, 172: 881-887. e7.

Loi P., Clinton M., B arboni B., Fulka Jr. J., Cappai P., F e il R., Moor R.M., Ptak G. (2002). Nuclei of nonviable ovine somatic cells develop into lambs after nuclear transplantation. Biol. Reprod., 67: 126-132.

Loi P., Matsukawa K., Ptak G., Clinton M., Fulka Jr J., N athan Y., Arav A. (2008). Freeze-dried somatic cells direct embryonic development after nuclear transfer. PLoS One, 3: e2978.

L o i P., M od li n s k i J.A., P t a k G. (2011). Interspecies somatic cell nuclear transfer: a salvage tool seeking first aid. Theriogenology, 76: 217-228.

L o i P., S a r a g u s ty J., P t a k G. (2014). Cloning the mammoth: a complicated task or just a dream? Adv. Exp. Med. Biol., 753: 489-502.

L o i P., I us o D., Czernik M., Ogura A. (2016). A new, dynamic era for somatic cell nuclear transfer? Trends Biotechnol., 34: 791-797.

Luo Y., Wang Y., Liu J., Lan H., Shao M., Yu Y., Quan F., Zhang Y. (2015). Production of transgenic cattle highly expressing human serum albumin in milk by phiC31 integrase-mediated gene delivery. Transgenic Res., 24: 875-883.

M a L.B., He X.Y., Wang F.M., Cheng T., L i u X.Y. (2014). Somatic cell reprogrammed by oocyte: process and barricade. Anim. Cells Syst. (Seoul), 18: 161-171. 
Ma cháty Z., Wang W.H., D a y B.N., Prather R.S. (1997). Complete activation of porcine oocytes induced by the sulfhydryl reagent, thimerosal. Biol. Reprod., 57: 1123-1127.

M a d h e s h i y a P.K., S a h a r e A.A., J y o t s a n a B., S ing h K.P., S a in i M., Ra ja A.K., K a ith S., S ingla S.K., C ha uh an M.S., Manik R.S., P a l t a P. (2015). Production of a cloned buffalo (Bubalus bubalis) calf from somatic cells isolated from urine. Cell. Reprogram., 3: 160-169.

Mahdi E., F a khris a d t H. (2012). Handmade cloning: an alternative technique for somatic cell nuclear transfer. Ann. Biol. Res., 3: 3043-3048.

Mann R.W.M., B a r t o 1 o m e i M.S. (2002). Epigenetic reprogramming in the mammalian embryo: struggle of the clones. Genome Biol., 3: 1003.1-1003.4.

Mann M.R., Chung Y.G., Nolen L.D., Verona R.I., Latham K.E., Bartolomei M.S. (2003). Disruption of imprinted gene methylation and expression in cloned preimplantation stage mouse embryos. Biol. Reprod., 69: 902-914.

Mat ob a S., Zhang Y. (2018). Somatic cell nuclear transfer reprogramming: mechanisms and applications. Cell Stem Cell., 23: 471-585.

Matoba S., Li u Y., Lu F., Iwabuchi K.A., Shen L., In o u e A., Zhang Y. (2014). Embryonic development following somatic cell nuclear transfer impeded by persisting histone methylation. Cell, 159: 884-895.

M it a li p o v S., Wolf D. (2009). Totipotency, pluripotency and nuclear reprogramming. Adv. Biochem. Eng. Biotechnol., 114: 185-199.

Mizutani E., Ohta H., K ishigami S., Van Thuan N., Hikichi T., Wakayam S., Kos a k a M., S a to E., Wa k a y a m a T. (2006). Developmental ability of cloned embryos from neural stem cells, Reproduction, 132: 849-857.

N a shun B., A k i y a m a T., Suzuk i M.G., A o k i F. (2011). Dramatic replacement of histone variants during genome remodeling in nuclear-transferred embryos. Epigenetics, 6: 1489-1497.

$\mathrm{N}$ i e m a n n H. (2016). Epigenetic reprogramming in mammalian species after SCNT-based cloning. Theriogenology, 86: 80-90.

$\mathrm{N}$ i e m a n n H., L u c a s - H a h n A. (2012). Somatic cell nuclear transfer cloning: Practical application and current legislation. Reprod. Dom. Anim., 47: 2-10.

$\mathrm{N}$ i e m a n n H., T i a n X.C., K ing W.A., L e e R.S.F. (2008). Epigenetic reprogramming in embryonic and foetal development upon somatic cell nuclear transfer. Reproduction, 135: 151-163.

Now a k-Imia lek M., Ku e s W.A., C arnw ath J.W., Nie mann H. (2011). Pluripotent stem cells and reprogrammed cells in farm animals. Microsc. Microanal., 17: 474-497.

O b a ck B., We $11 \mathrm{~s}$ D. (2002). Donor cells for nuclear cloning: many are called, but few are chosen. Cloning Stem Cells, 4: 147-168.

Ogura A., Inoue K., Tak a no K., Wa ka y a ma T., Yanagima chi R. (2000). Birth of mice after nuclear transfer by electrofusion using tail tip cells. Mol. Reprod. Dev., 57: 55-59.

Olivera R., Moro L.N., Jordan R., Luzzani C., Miriuka S., Radrizzani M., Dona d e u F.X., Vi c h e r a G. (2016). In vitro and in vivo development of horse cloned embryos generated with iPSCs, mesenchymal stromal cells and fetal or adult fibroblasts as nuclear donors. PLoS One 11 (10): e0164049.

Olivera R., Moro L.N., Jordan R., Pallarols N., Guglielminetti A., Luzzani C., M iriuka S.G., Vi cher a G. (2018). Bone marrow mesenchymal stem cells as nuclear donors improve viability and health of cloned horses. Stem Cells Cloning, 11: 13-22.

Ono T., Mizutani E., Li C., Wak a y a a T. (2008). Nuclear transfer preserves the nuclear genome freeze-dried mouse cells. J. Reprod. Dev., 54: 486-491.

O n o Y., S h i m o z a w a N., I t o M., K o n o T. (2001). Cloned mice from fetal fibroblast cells arrested at metaphase by a serial nuclear transfer. Biol. Reprod., 64: 44-50.

O p i e la J., S a m i e c M. (2013). Characterization of mesenchymal stem cells and their application in experimental embryology. Pol. J. Vet. Sci., 16: 593-599.

Opiela J., S a mi e c M., B ochenek M., Lipiński D., Romanek J., Wilczek P. (2013). DNA aneuploidy in porcine bone marrow-derived mesenchymal stem cells undergoing osteogenic and adipogenic in vitro differentiation. Cell. Reprogram., 15: 425-434.

O p i e la J., S a m i e c M., R o m a n e k J. (2017). In vitro development and cytological quality of inter-species (porcine $\rightarrow$ bovine) cloned embryos are affected by trichostatin A-dependent epigenomic modulation of adult mesenchymal stem cells. Theriogenology, 97: 27-33. 
Park D.S., Cerrone M., Morley G., Vasquez C., Fowler S., Liu N., B ernstein S.A., Liu F.Y., Zhang J., Rogers C.S., Priori S.G., Chinitz L.A., F ishman G.I. (2015) Genetically engineered SCN5A mutant pig hearts exhibit conduction defects and arrhythmias. J. Clin. Invest., 125: 403-412.

P o l e a j e va I.A., Che n S.H., Va u g h t T.D.,P a g e R.L., Mu 11 in s J., B a 11 S., D a i Y., B o o ne J., Walker S., Ay ares D.L., Colman A., Cam p be 11 K.H. (2000). Cloned pigs produced by nuclear transfer from adult somatic cells. Nature, 407: 505-509.

Prather R.S., K uh holzer B., L a i L., P a rk K.W. (2000). Changes in the structure of nuclei after transfer to oocytes. Cloning, 2: 117-122.

Priy a D., S elokar N.L., R aja A.K., S a in i M., S a hare A.A., N a la N., P a lt a P., Chau h a n M.S., M a n ik R.S., S ing la S.K. (2014). Production of wild buffalo (Bubalus arnee) embryos by interspecies somatic cell transfer using domestic buffalo (Bubalus bubalis) oocytes. Reprod. Dom. Anim., 49: 343-351.

R a k h a A. (2015). Cloning efficiency and a comparison between donor cell types. Cloning Transgen., 4: 141 .

Richter A., Kurome M., Kessler B., Zakhartchenko V., Klymiuk N., Nagashim a H., Wolf E., W u e n s c A. (2012). Potential of primary kidney cells for somatic cell nuclear transfer mediated transgenesis in pig. BMC Biotechnol., 12: 84.

R i d e o u t W.M.3rd., Eg g a n K., J a e $\mathrm{n}$ i s c h R. (2001). Nuclear cloning and epigenetic reprogramming of the genome. Science, 293: 1093-1098.

$\mathrm{S}$ a a d e $1 \mathrm{~d}$ in I.M., K i m S.J., C h o i Y.B., L e e B.C. (2014). Improvement of cloned embryos development by co-culturing with parthenotes: a possible role of exosomes/microvesicles for embryos paracrine communication. Cell. Reprogram., 16: 223-234.

S a e ki K., Hos hino Y., Taniguchi S. (2014). Biological age of cloned animals. Principles of Cloning. 2nd ed., 33: 419-428.

S a in i M., S e lok ar N.L., A graw al H., S ingla S.K., Chauhan M.S., Manik R.S., Pa 1 t a P. (2006). Treatment of buffalo (Bubalus bubalis) donor cells with trichostatin A and 5-aza-2'deoxycytidine alters their growth characteristics, gene expression and epigenetic status of cloned embryos. Reprod. Fert. Develop., 28: 824-837.

S a m i e c M. (2004). Development of pig cloning studies: past, present and future. J. Anim. Feed Sci., 13: $211-238$.

$\mathrm{S}$ a m i e c M. (2005 a). The effect of mitochondrial genome on architectural remodeling and epigenetic reprogramming of donor cell nuclei in mammalian nuclear transfer-derived embryos. J. Anim. Feed Sci., 14: 393-422.

$\mathrm{S}$ a $\mathrm{m}$ i e c M. (2005 b). The role of mitochondrial genome (mtDNA) in somatic and embryo cloning of mammals. A review. J. Anim. Feed Sci., 14: 213-233.

S a m i e c M., Skrzy s z ow s k a M. (2005 a). Molecular conditions of the cell nucleus remodelling/ reprogramming process and nuclear-transferred embryo development in the intraooplasmic karyoplast injection technique: a review. Czech J. Anim. Sci., 50: 185-195.

S a mi e c M., Skrzys zowska M. (2005 b). Microsurgical nuclear transfer by intraooplasmic karyoplast injection as an alternative embryo reconstruction method in somatic cloning of pigs and other mammal species; application value of the method and its technical advantages: a review. Czech J. Anim. Sci., 50: 235-242.

S a m i e c M., S k r z y s z o w s k a M. (2010 a). Preimplantation developmental capability of cloned pig embryos derived from different types of nuclear donor somatic cells. Ann. Anim. Sci., 10: 385-398.

S a mi e c M., Skrzys zow s k a M. (2010 b). The use of different methods of oocyte activation for generation of porcine fibroblast cell nuclear-transferred embryos. Ann. Anim. Sci., 10: 399-411.

S a mi e c M., Skrzy s z ow s k a M. (2011 a). Transgenic mammalian species, generated by somatic cell cloning, in biomedicine, biopharmaceutical industry and human nutrition/dietetics - recent achievements. Pol. J. Vet. Sci., 14: 317-328.

S a m i e c M., S krzy s z ow s k a M. (2011 b). The possibilities of practical application of transgenic mammalian species generated by somatic cell cloning in pharmacology, veterinary medicine and xenotransplantology. Pol. J. Vet. Sci., 14: 329-340.

S a mi e c M., Skrzys zow s k M. (2012 a). Roscovitine is a novel agent that can be used for the activation of porcine oocytes reconstructed with adult cutaneous or fetal fibroblast cell nuclei. Theriogenology, 78: 1855-1867. 
S a m i e c M., S k r z y s z o w s k a M. (2012 b). High developmental capability of porcine cloned embryos following trichostatin A-dependent epigenomic transformation during in vitro maturation of oocytes pre-exposed to $R$-roscovitine. Anim. Sci. Pap. Rep., 30: 383-393.

$\mathrm{S}$ a $\mathrm{m}$ i e c M., S krzy s z o w s k a M. (2013). Assessment of in vitro developmental capacity of porcine nuclear-transferred embryos reconstituted with cumulus oophorus cells undergoing vital diagnostics for apoptosis detection. Ann. Anim. Sci., 13: 513-529.

S a m i e c M., S kr z y s z o w s k a M. (2014). Biological transcomplementary activation as a novel and effective strategy applied to the generation of porcine somatic cell cloned embryos. Reprod. Biol., 14: $128-139$.

S a m i e c M., S k r zy s z o w s k a M. (2018 a). Can reprogramming of overall epigenetic memory and specific parental genomic imprinting memory within donor cell-inherited nuclear genome be a major hindrance for the somatic cell cloning of mammals? - a review. Ann. Anim. Sci., 18: 623-638.

S a m i e c M., S kr z y s z o w s k a M. (2018 b). Intrinsic and extrinsic molecular determinants or modulators for epigenetic remodeling and reprogramming of somatic cell-derived genome in mammalian nuclear-transferred oocytes and resultant embryos. Pol. J. Vet. Sci., 21: 217-227.

S a mi e c M., Skrzys zow s ka M., Li p ińs ki D. (2012). Pseudophysiological transcomplementary activation of reconstructed oocytes as a highly efficient method used for producing nucleartransferred pig embryos originating from transgenic foetal fibroblast cells. Pol. J. Vet. Sci., 15: 509-516.

S a m i e c M., Skrzyszows ka M., Opi ela J. (2013 a). Creation of cloned pig embryos using contact-inhibited or serum-starved fibroblast cells analysed intra vitam for apoptosis occurrence. Ann. Anim. Sci., 13: 275-293.

S a miec M., Skrzyszowska M., B ochenek M. (2013 b). In vitro development of porcine nuclear-transferred embryos derived from fibroblast cells analysed cytometrically for apoptosis incidence and accuracy of cell cycle synchronization at the G0/G1 stages. Ann. Anim. Sci., 13: 735-752.

S a m i e c M., O p i e la J., Li p ińs ki D., R o man ek J. (2015). Trichostatin A-mediated epigenetic transformation of adult bone marrow-derived mesenchymal stem cells biases the in vitro developmental capability, quality, and pluripotency extent of porcine cloned embryos. Biomed Res. Int., 2015: 814686 .

S a m i e c M., R o manek J., Li piński D., O pi e la J. (2019). Expression of pluripotency-related genes is highly dependent on trichostatin A-assisted epigenomic modulation of porcine mesenchymal stem cells analysed for apoptosis and subsequently used for generating cloned embryos. Anim. Sci. J., 90: 1127-1141.

S a unders C.M., Larman M.G., P arrington J., Cox L.J., Roys e J., B layney L.M., S w a n K K., L a i F.A. (2002). PLC zeta: a sperm-specific trigger of $\mathrm{Ca}^{2+}$ oscillations in eggs and embryo development. Development, 129: 3533-3544.

Schaetzlein S., Lucas-Hahn A., Lemme E., Kues W.A., Dorsch M., Manns M.P., $\mathrm{N}$ i e mann H., Rudolph K.L. (2004). Telomere length is reset during early mammalian embryogenesis. Proc. Natl. Acad. Sci. USA, 101: 8034-8038.

S c hult z R.M. (1993). Regulation of zygotic gene activation in the mouse. Bioessays, 15: 531-538.

S churmann A., We 11 s D.N., O b a c k B. (2006). Early zygotes are suitable recipients for bovine somatic nuclear transfer and result in cloned offspring. Reproduction, 132: 839-848.

Selokar N.L., Saini M., Agrawal H., Palta P., Chauhan M.S., Manik R., Sing1 a S.K. (2016). Buffalo (Bubalus bubalis) SCNT embryos produced from somatic cells isolated from frozen-thawed semen: effect of trichostatin A on the in vitro and in vivo developmental potential, quality and epigenetic status. Zygote, 4: 549-553.

Shiels P.G., Kind A.J., Campbell K.H., Waddington D., Wilmut I., Colman A., S c hni e k e A.E. (1999). Analysis of telomere lengths in cloned sheep. Nature, 399: 316-317.

Shin T.Y., Kraemer D., Pryor J., Liu L., Rugila J., Howe L., Buck S., Murphy K., Ly on s L., We s thus in M. (2002). A cat cloned by nuclear transplantation. Nature, 415: 859.

Shufaro Y., Reubin off B.E. (2017). Nuclear treatment and cell cycle synchronization for the purpose of mammalian and primate somatic cell nuclear transfer (SCNT). Humana Press, New York, NY. Methods Mol. Biol., 1524: 289-298.

Skrzys zowska M., S a mi e c M. (2020). Enhancement of in vitro developmental outcome of cloned goat embryos after epigenetic modulation of somatic cell-inherited nuclear genome with trichostatin A. Ann. Anim. Sci., 20: 97-108. 
Skrzyszowska M., Kątska L., Ryńska B., Kania G., Smorąg Z., Pieńkowski M. (2002). In vitro developmental competence of domestic cat embryos after somatic cloning: a preliminary report. Theriogenology, 58: 1615-1621.

S krzys zow s ka M., S m or ąg Z., Słomski R., Kątska-Ks iążki ewicz L., Kalak R., Michalak E., Wielgus K., Lehmann J., Lipiński D., Szalata M., Pławski A., S a mi e c M., J u r a J., Gaj d a B., Ry ń s ka B., P i eń k o w s ki M. (2006). Generation of transgenic rabbits by the novel technique of chimeric somatic cell cloning. Biol. Reprod., 74: 1114-1120.

S krzy s z ow s k a M., S a mi e c M., Sło m sk i R., Li piń s ki D., Mały E. (2008). Development of porcine transgenic nuclear-transferred embryos derived from fibroblast cells transfected by the novel technique of nucleofection or standard lipofection. Theriogenology, 70: 248-259.

S o n g S.H., L e e K.L., X u L., J o o M.D., H w a n g J.Y., O h S.H., K o n g I.K. (2019). Production of cloned cats using additional complimentary cytoplasm. Anim. Reprod. Sci., 208: 106125.

Srirattana K., St. John J.C. (2017). Manipulating the mitochondrial genome to enhance cattle embryo development. G3 (Bethesda), 7: 2065-2080.

Ste inborn R., S chinogl P., Wells D.N., B ergthale r A., Mulle r M., B rem G. (2002). Coexistence of Bos taurus and Bos indicus mitochondrial DNAs in nuclear transfer-derived somatic cattle clones. Genetics, 162: 823-829.

S tr a hl B.D., A 11 i s C.D. (2000). The language of covalent histone modifications. Nature, 403: 41-45.

Sullivan E.J, Kas in ath a n S., Kas in a than P., R obl J.M., C o 11 a s P. (2004). Cloned calves from chromatin remodeled in vitro. Biol. Reprod., 70: 146-153.

S un J.M., S pen cer V.A., Chen H.Y., Li L., D a vi e J.R. (2003). Measurement of histone acetyltransferase and histone deacetylase activities and kinetics of histone acetylation. Methods, 31: $12-23$.

Suzuki T., Yoshida N., S uzuki E., O ku d a E., P erry A.C. (2010). Full-term mouse development by abolishing $\mathrm{Zn}^{2+}$-dependent metaphase II arrest without $\mathrm{Ca}^{2+}$ release. Development, 137: 2659-2669.

Tach ib an a M., A m a to P., S parman M., Gut i errez N.M., Tip pner-Hedges R., Ma H., Kang E., Fulati A., Lee H.S., Sritanaudomchai H., Masterson K., Larson J., Eaton D., S adler-Fredd K., B attaglia D., Lee D., Wu D., Jensen J., Patton P., G okhale S., S tou ffer R.L., Wolf D., Mit a li pov S. (2013). Human embryonic stem cells derived by somatic cell nuclear transfer. Cell, 153: 1228-1238.

T a m a d a H., K i k y o N. (2004). Nuclear reprogramming in mammalian somatic cell nuclear cloning. Cytogenet. Genome. Res., 105: 285-291.

Tanabe Y., Kuw y a ma H., Wakay a ma S., Nagatomo H., Ooga M., Ka mimura S., K i s h i g a m i S., Wa k a y m a T. (2017). Production of cloned mice using oocytes derived from ICR-outbred strain. Reproduction, 154: 859-866.

Ta o T., Ma chaty Z., A b e y de er a L.R., D a y B.N., P r a the r R.S. (2000). Optimization of porcine oocyte activation following nuclear transfer. Zygote, 8: 69-77.

Tecirlioglu R.T., French A.J., Lew is I.M., Vajt a G., Korfiat is N.A., Ha 11 V.J., Rud dock N.T., Cooney M.A., Trouns on A.O. (2003). Birth of a cloned calf derived from a vitrified hand-made cloned embryo. Reprod. Fert. Develop., 15: 361-366.

Ti a n X.C., Kubota C., Enright B., Yang X. (2003). Cloning animals by somatic cell nuclear transfer-biological factors. Reprod. Biol. Endocrinol., 13: 98.

T i a n X.C., X u J., Yang X. (2000). Normal telomere length found in cattle. Nat. Genet., 26: $272-273$.

To n g W.F., Ng Y.F., Ng S.C. (2002). Somatic cell nuclear transfer (cloning): Implications for the medical practitioner. Singapore Med. J., 43: 369-376.

Vaj t a G. (2007). Handmade cloning: the future way of nuclear transfer? Trends Biotechnol., 25: 250253.

Vaj t a G., H o $1 \mathrm{~m}$ P., G reve T., C a 11 e s e n H. (1996). Overall efficiency of in vitro embryo production and vitrification in cattle. Theriogenology, 45: 683-689.

Vaj t a G., P e ura T.T., Holm P., Pald i A., Greve T., Trouns on A.O., Call e s e n H. (2000). New method for culture of zona-included or zona-free embryos: the well of the well (WOW) system. Mol. Reprod. Dev., 55: 256-264.

Vaj t a G., L e w is I.M., H y t t e 1 P., Th ou a s G.A., Troun s o n A.O. (2001). Somatic cell cloning without micromanipulators. Cloning, 3: 89-95. 
Vaj t a G., Kr a g h P.M., M a n g o N.R., C a 11 e s e n H. (2005). Hand-made cloning approach: potentials and limitations. Reprod. Fert. Develop., 17: 97-112.

Verma G., Arora J.S., Sethi R.S., Mukhopadhyay C.S., Verma R. (2015). Handmade cloning: recent advances, potential and pitfalls. J. Anim. Sci. Biotechnol., 6: 43.

W a k a y a m a T., Ya n a g i m a c h i R. (2001). Mouse cloning with nucleus donor cells of different age and type. Mol. Reprod. Dev., 58: 376-383.

Wa k a y a m a T., P e rry A.C., Zu c c ot ti M., Johns on K.R., Yan a g i m a chi R. (1998). Fullterm development of mice from enucleated oocytes injected with cumulus cell nuclei. Nature, 394 : 369-374.

Wa ka y a ma S., Ohta H., Hikichi T., Mizutani E., I waki T., Kanagawa O., Waka ya $\mathrm{m}$ a T. (2008). Production of healthy cloned mice from bodies frozen at -20 degrees $\mathrm{C}$ for 16 years. Proc. Natl. Scad. Sci. USA, 105: 17318-17322.

Wang H., Cu i W., Meng C., Zhang J., Li Y., Qian Y., Xing G., Zha o D., Ca o S. (2018). $\mathrm{MC} 1568$ enhances histone acetylation during oocyte meiosis and improves development of somatic cell nuclear transfer embryos in pig. Cell Reprogram, 20: 55-65.

Wang X., Q u J., Li J., H e H., L i u Z., H u a n Y. (2020). Epigenetic reprogramming during somatic cell nuclear transfer: recent progress and future directions. Front. Genet., 11: 205.

Wan i N.A., Wern ery U., H a s s an F.A.H., Wernery R., S k i d m or e J.A. (2010). Production of the first cloned camel by somatic cell nuclear transfer. Biol. Reprod., 82: 373-379.

Wilmut J., Schnieke A.E., McWhir J., Kind A.J., Campbel1 K.H. (1997). Viable offspring derived from fetal and adult mammalian cells. Nature, 385: 810-813.

Wong T., Mc Grath J.A., N avs aria H. (2007). The role of fibroblasts in tissue engineering and regeneration. Br. J. Dermatol., 156: 1149-1155.

Woods G.L., White K.L., Vanderwall D.K., Li G.P., A s ton K.I., Bunch T.D., M e e r d o L.N., P a t e B.J. (2003). A mule cloned from fetal cells by nuclear transfer. Science, 30: 106.

Wu C.F., Z hang D.F., Z hang S., S u n L., L i u Y., D a i J.J. (2019). Optimizing treatment of DNA methyltransferase inhibitor RG108 on porcine fibroblasts for somatic cell nuclear transfer. Reprod. Domest. Anim., 54: 1604-1611.

Xi a o J., L i Q., Qu P., Zh ang Z., P a n S., Wang Y., Zh ang Y. (2016). Isolation of bovine skinderived precursor cells and their developmental potential after nuclear transfer. Cell. Reprogram., 18: $411-418$.

Xu L., Mesalam A., Lee K.L., Song S.H., Khan I., Chowdhury M.M.R., Lv W., K o n g I.K. (2019). Improves the in vitro developmental competence and reprogramming efficiency of cloned bovine embryos by additional complimentary cytoplasm. Cell. Reprogram., 21: 51-60.

Yamazaki Y., Low E., Marikawa Y., Iwahashi K., Bartolomei M., Mc Carrey J., Yan a g im a chi R. (2005). Adult mice cloned from migrating primordial germ cells. Microsc. Microanal., 11: 122-123.

Yang X., Wu X., Yang Y., Gu T., Hong L., Zheng E., Xu Z., Zeng F., Shi J., Zhou R., Cai G., Wu Z., Li Z. (2019). Improvement of developmental competence of cloned male pig embryos by short hairpin ribonucleic acid (shRNA) vector-based but not small interfering RNA (siRNA)-mediated RNA interference (RNAi) of Xist expression. J. Reprod. Dev., 18: 533-539.

Yuan Y., Kris her R.L. (2012). In vitro maturation (IVM) of porcine oocytes. In: Germline Development. Methods and Protocols, Chann W.Y., Blomberg L.A. (eds.). Springer, New York, NY. Methods Mol. Biol., 825: 183-198.

Z a g n o n i M. (2012). Miniaturised technologies for the development of artificial lipid bilayer systems. Lab Chip., 12: 1026-1039.

Zhang P., Zhang Y., Dou H., Yin J., Chen Y., Pang X., Vajta G., Bolund L., Du Y., M a R.Z. (2012). Handmade cloned transgenic piglets expressing the nematode fat-1 gene. Cell. Reprogram., 14: 258-266.

Zhang P., Liu P., Dou H., Chen L., Chen L., Lin L., Tan P., Vajta G., Gao J., Du Y., M a R.Z. (2013). Handmade cloned transgenic sheep rich in omega-3 fatty acids. PLoS One, 8 (2): e55941.

Zhou Q., Renard J.P., Fries G.L., Brochard V., Beaujean N., Cherifi Y., Fraic hard A., Cozzi J. (2003). Generation of fertile cloned rats by regulating oocyte activation. Science, 302: 117. 
Zhou C., Wang Y., Zhang J., S u J., An Q., Li u X., Zhang M., Wang Y., Li u J., Zhang Y. (2019). H3K27me3 is an epigenetic barrier while KDM6A overexpression improves nuclear reprogramming efficiency. FASEB J., 33: 4638-4652.

Received: 29 VIII 2020

Accepted: 26 I 2021 